\title{
Vaginal Dosage Form
}

National Cancer Institute

\section{Source}

National Cancer Institute. Vaginal Dosage Form. NCI Thesaurus. Code C69048.

A substance intended for administration in or around the vagina. 